\title{
Industrial outcomes
}

Academic scientists funded by large companies publish, patent and are cited less often than those supported by smaller firms or other sources, a study says. Research Grants, Sources of Ideas and the

Nehal Mehta is the inaugural Lasker Clinical Research Scholar - the first recipient of an award established by the US National Institutes of Health (NIH) and the Lasker Foundation in New York. Last month, Mehta moved from the University of Pennsylvania (UPenn) in Philadelphia to the NIH campus in Bethesda, Maryland, where he is studying links between cardiovascular disease and the chronic inflammation associated with conditions such as diabetes, obesity and psoriasis. The award affords a serious career boost: after 5-7 years with positive reviews, Mehta will have the option of getting tenure at the NIH or applying - with funding in tow - to an academic institution.

You trained as a medical doctor. When did you realize that you also wanted to do research? It started with my internal-medicine residency. I had a lot of unanswered questions - for instance, why do certain people have heart attacks when they have atherosclerosis (hardening of the arteries) and others don't? My main mentor at UPenn encouraged me to investigate such questions. I enrolled about 80 people in his clinical study asking how inflammation affects molecular pathways that lead to atherosclerosis. He opened my eyes to clinical research.

What benefits does the Lasker award bring? It provides the resources to develop my career - not just money, but also crucial elements such as core facilities, access to patients and travel opportunities. The scholarship can last up to 12 years; clinical research is very time consuming, mostly because of clinical trials. This award comes once in a lifetime: I have the chance to run my own programme and see patients at the NIH Clinical Center, a world-class research hospital, without the barriers that face many young investigators, such as the need to secure funding.

\section{What is your research focus?}

My lab is poised to answer whether inflammation is simply a by-product of certain conditions, or a driver of cardiovascular disease. One of our studies asks whether treating chronic inflammation improves markers of cardiovascular health, such as how the body handles cholesterol and sugar.

\section{What are your plans for the NIH?}

I have a three-pronged approach. We are starting a national effort to obtain skin, fat and blood samples from people with psoriasis to

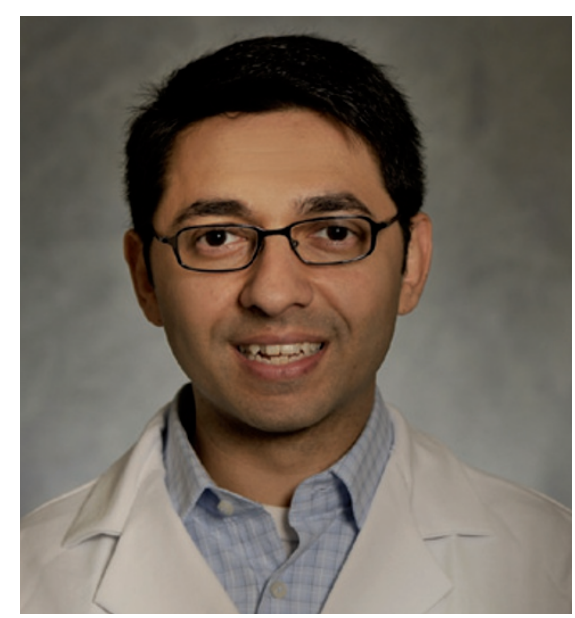

understand the dysregulation of molecular and cellular pathways related to cardiovascular and metabolic diseases. The second arm will bring patients into the NIH Clinical Center to study risk factors for cardiometabolic disease and assess vascular inflammation. Finally, we will examine cardiometabolic pathways in animals and cell culture.

You plan to continue working at UPenn. How will you balance this with your job at the NIH? I will be an adjunct faculty member at UPenn, and will go there every seven weeks to see people with psoriasis in my preventive cardiology programme. Hopefully most of them will come to the NIH; we will continue to enrol patients at UPenn but do assays and imaging analysis at the NIH. I have roots at UPenn: mentors are now collaborators. And I have an excellent nurse.

\section{Did you ever consider getting a PhD?}

I have thought about it, but I don't think it is absolutely necessary. There are some things I struggle with in the lab, such as operating certain equipment, but I can solve those problems by surrounding myself with great scientists. I do believe that a certain amount of advanced training is necessary. I have a master's degree in clinical epidemiology, which helps me to do high-level clinical research, design studies and work in a lab.

How do you juggle medicine and research? My patients provide me with rich samples and rich questions. I get a lot out of each activity: by seeing patients, I am helping people but also doing research.

INTERVIEW BY CHARLOTTE SCHUBERT
Effects on Academic Research, released on 29 July by the Centre for European Economic Research in Mannheim, Germany, polled researchers at 46 German universities. Co-author Cornelia Lawson, an economist at the University of Turin, Italy, says that large grant-giving firms might modify the focus of the work during the project so that there are not enough data to publish after the grant. They also tend to fund applied research, which may be cited less often, she says. The study notes that industrial sponsorship has been on the rise globally for several years.

\section{EQUALITY}

\section{Awards for women}

Five early-career female researchers from Africa, the Middle East, Asia, Latin America and the Caribbean are to be honoured with US\$5,000 Elsevier Foundation Awards in a programme to encourage women to pursue science in nations that lack scientific expertise, resources and gender equality. "They are not given the opportunity to do good science," says Peter McGrath, a programme officer for co-sponsor TWAS, the academy of sciences for the developing world in Trieste, Italy. "This is a way to bring their work to the international forefront." Nominations for researchers from 81 eligible nations who earned $\mathrm{PhDs}$ in the past 10 years will be accepted until 30 September.

\section{GERMANY}

\section{Initiative criticized}

Germany’s €4.6-billion (US\$5.6-billion) Excellence Initiative has not helped universities to distinguish themselves, according to a briefing (go.nature.com/ nsjpca) released on 22 June by the Social Science Research Center Berlin (WZB). The report says that institutions are concentrating on basic research to the detriment of teaching and applied research "When we talk about excellence, we also have to talk about conditions for excellent teaching," says co-author Dagmar Simon, head of science-policy studies at the WZB. The scheme to make Germany's university system more competitive is in its second phase (see Nature 487, 519-521; 2012). 